\title{
Unlocking the Opening Processes of the South China Sea
}

\author{
by Chun-Feng Li, Pinxian Wang, Dieter Franke, Jian Lin, and Jun Tian
}

doi:10.2204/iodp.sd.14.07.2012

\section{Introduction}

The South China Sea (SCS) is a classical representative of western Pacific marginal seas (Figs. 1, 2). It developed from continental margin rifting, and its central portion is floored with oceanic crust. Despite its relatively short evolutionary history, compelling research opportunities abound for a multitude of key tectonic processes ranging from rifting through seafloor spreading to subduction, as well as for the cyclical climatic changes with broad regional impact. Its relatively small size and young age compared to major ocean basins facilitate tectonic comparisons between conjugate continental margins and make the entire basin accessible through a single expedition of scientific ocean drilling. These attributes make the SCS an exemplary natural laboratory for studying continental break-up, sedimentary basin formation, mantle and lithosphere evolution, and land-ocean interactions. However, lack of any deep scientific borehole in the

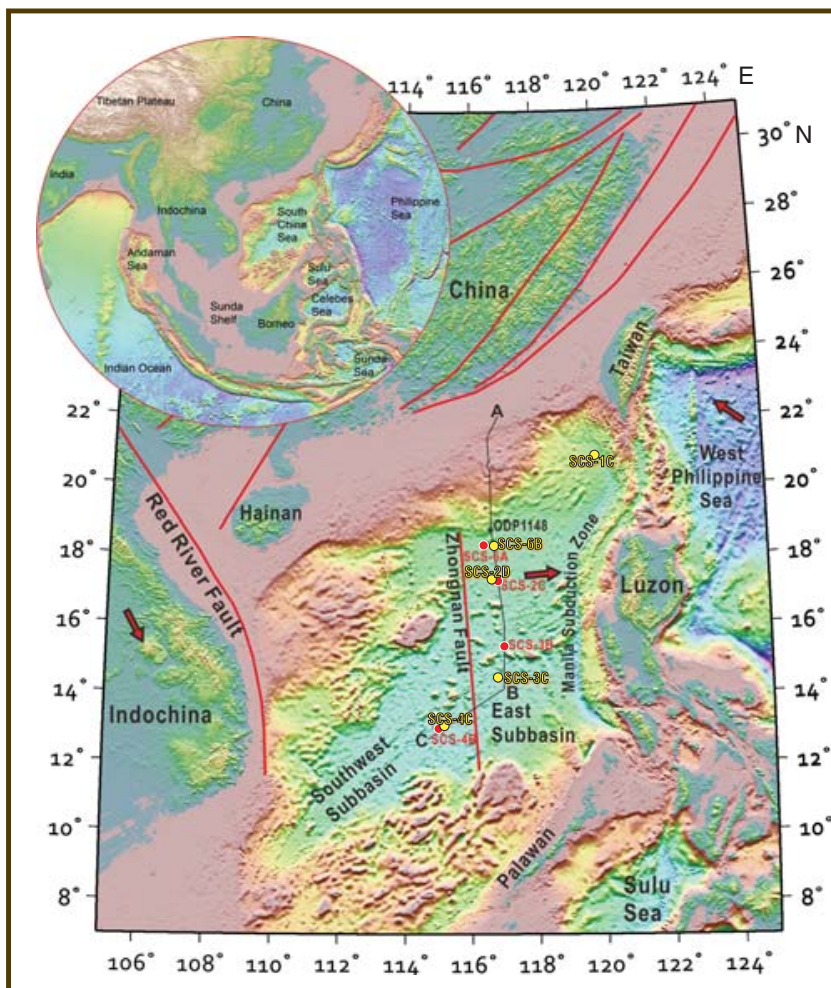

Figure 1. Regional topography and tectonic framework of Southeast Asia (from Shi and Li, 2012). Data based on Smith and Sandwell (1997). Red lines mark major faults. Red and yellow solid points are locations of the proposed drilling sites (red-primary sites; yellowalternate sites). The black lines labeled with $A B$ and $B C$ are seismic sections shown in Fig. 3. Red arrows indicate the direction of plate movement. central SCS basin leaves a gap in understanding of the opening mechanisms, timing of the onset and termination of seafloor spreading, and environmental history in the region.

To advance research of Southeast Asia and the SCS through scientific ocean drilling, an international workshop entitled "Unlocking the Opening Processes of the South China Sea” was held on 31 January-1 February 2012 in Shanghai, China. It was the first international workshop devoted to scientific ocean drilling in the SCS in the recent decade. Building on an existing Integrated Ocean Drilling Program (IODP) drilling proposal (Li et al., 2012), this workshop sought contributions from the broad international community, including scientists from non-IODP member states that have a strong scientific interest in the SCS. The overarching goal of the workshop was to develop the most efficient research and drilling strategy to address key questions in tectonics and environmental history of the SCS within a single, initial IODP expedition.

The workshop hosted sixty-five participants from fifteen countries and regions, including scientists from several non-IODP member states surrounding the SCS (Indonesia, Malaysia, Philippines, Singapore, Thailand, and Vietnam). The workshop was jointly sponsored by the IODP-MI, IODP-China, the South China Sea Deep (SCSD) Program of the National Natural Science Foundation of China (NSF-C), and the State Key Laboratory of Marine Geology at Tongji University, China. The lead conveners were Pinxian Wang and Chun-Feng Li of Tongji University, and Dieter Franke of the Federal Institute for Geosciences and Natural Resources, Germany.

The workshop was charged with the following three tasks.

1. To identify key scientific questions on tectonics and environmental history of a marginal sea that can be addressed through scientific drilling in the SCS, and to develop an efficient research and drilling strategy to address these questions

2. To recommend ways to improve the IODP Proposal 735-CPP through focusing drilling objectives, refining drilling targets, and augmenting site survey data

3. To foster cooperation in research of the Southeast Asia region through engagement of a broad international scientific community including scientists 
from non-IODP member states surrounding the SCS

\section{Scientific Background}

With its area of 3.5 million $\mathrm{km}^{2}$ and maximal depth of $5500 \mathrm{~m}$, the SCS is one of the largest marginal seas in the world (Figs. 1, 2). Since the Late Mesozoic, it has been at the center stage of many first-order tectonic and paleoclimatic events. Mesozoic subduction of the paleo-Pacific plate, a fragment of which developed roughly along the present-day northern SCS continental margin (Taylor and Hayes, 1983), gradually dispelled Paleo-Tethys and built a massive orogen in Southeast Asia. However, during the transition from the Early to Late Cretaceous, all supportive evidence of the subduction zone disappeared, while regional extension started to prevail (Shi and $\mathrm{Li}, 2012$ ). This was followed by the Cenozoic opening of the SCS, via continental break-up and subsequently seafloor spreading. The early work of Taylor and Hayes $(1980,1983)$ and Briais et al. (1993) suggested that the SCS opened from $\sim 32$ Ma to 16 Ma during the Oligocene and Early Miocene. Presently located between the Earth's largest ocean and the largest continent and being near the Pacific Warm Pool, the SCS also plays a significant role in affecting the global climate system (Wang and Li, 2009).

The SCS is uniquely situated for studying continental break-up, basin formation, and seafloor spreading processes for several reasons.

1. It is a classical representative of western Pacific marginal seas that developed from continental break-up and has evolved into seafloor spreading.

2. The SCS is located at the junction of the Eurasian, Pacific, and Indo-Australian plates and therefore is sensitive to tectonic and climatic changes associated with the surrounding plates.

3. Its relatively small size and young age facilitates easy tectonic comparisons between the two conjugate continental margins.

4. Despite its short evolutionary history, the SCS has undergone a complete Wilson cycle from continental break-up and seafloor spreading to subduction. Therefore, it is well suited for studying various plate boundary activities, such as oceanic subduction (e.g., the Manila Trench), strike-slip faulting (e.g., the Red River Fault), and active orogenic processes (e.g., Taiwan).

5. The rifting style of the SCS margins may represent an intermediary form of continental extension between the end-member scenarios of highly magma-rich (e.g., North Atlantic margins) and magma-poor or hyperextended (e.g., Iberia and Newfoundland) margins.
6. The SCS is associated with high sedimentation rates and carbonate preservation, providing comple- mentary records to those from the poorly preserved carbonates in the western Pacific Ocean.

All these attributes make the SCS an ideal natural laboratory for studying continental break-up, basin formation, deep mantle evolution, and land-ocean interactions. However, there is not yet one single deep drilling well in the central SCS basin targeting the oceanic crust or its transition from the continental crust. This leaves a large gap in understanding the opening mechanisms and timing of the onset and termination of seafloor spreading in the SCS.

In 1999, ODP conducted the first deep scientific drilling, Leg 184, in the SCS, focusing primarily on Asian monsoon and environmental history of the region (Wang et al., 2000). Leg 184 cored seventeen holes at Sites 1143-1148 in the SCS and recovered 5463 meters of sediment. The suite of sites yields an almost continuous record of the environmental history of the SCS during the last $32 \mathrm{Ma}$. Leg 184, however, was neither sited for recovering pre-rift and syn-rift strata, nor did it reach the oceanic crust basement. This leaves the SCS basin completely unconstrained in terms of its formation history.

\section{Scientific Debates on the Tectonics of the SCS}

Among the continents of the world, Asia has been subjected to the most significant Cenozoic deformation. Coincident with the large-scale deformation of Asia, many of the marginal seas in the western Pacific stopped spreading during the early Miocene. However, the opening mechanisms and driving forces for the SCS basin are still debated. One model links the opening of the SCS basin with the Red River fault zone, which has at least 500-600 km of left-lateral displacement created during the Oligocene and Miocene 
(Tapponnier et al., 1982; Briais et al., 1993). Alternative models relate the opening of the SCS to subduction under Borneo (Taylor and Hayes, 1980, 1983; Holloway, 1982; Hall, 1996) and the influence of subduction beneath the Philippines, driving a back-arc type of extension in the overriding plate (Taylor and Hayes, 1980).

Another major topic of debate is the timing of the onset and termination of seafloor spreading in the SCS. Largely based on interpretation of magnetic anomalies, estimations of the oceanic crust age for the east sub-basin were 32-17 Ma (Taylor and Hayes, 1980, 1983), 32-16 Ma (Briais et al., 1993; Li and Song, 2012), and 31-20.5 Ma (Barkhausen and Roeser, 2004). For the southwest sub-basin, the estimations of the oceanic crust age differ widely from 27-16 Ma (Briais et al., 1993; Li and Song, 2012), to 25-20.5 Ma (Barkhausen and Roeser, 2004), and to 42-35 Ma (Yao et al., 1994). Furthermore, Hsu et al. (2004) proposed the existence of oceanic crust as old as $37 \mathrm{Ma}$ on the northeast part of the SCS. Such large discrepancies in the proposed magnetic ages of the oceanic crust point to the critical importance of direct sampling and dating the oceanic basement rocks through deep drilling in the SCS.

\section{Workshop Deliberation}

The two-day workshop consisted of a mix of presentations, breakout sessions, and plenary discussion. The meeting featured five keynote addresses, thirty oral presentations, and twenty-five posters. These presentations covered a wide range of topics pertinent to tectonics and environmental history of Southeast Asia and the SCS. While the majority of presentations focused on the tectonic and magmatic evolution of the region and comparisons with other examples of continental rifting, basin formation, and seafloor spreading, participants also showcased work on paleoceanography, sedimentology, and biogeochemistry of the region. In addition, the meeting featured a presentation on the IODP proposal process, commentary on the current IODP drilling engineering capability, and a review of the previous panel comments and recommendations on the IODP Proposal 735-CPP.

The workshop devoted a significant amount of time to breakout sessions and plenary discussion. The breakout subgroups were charged with developing recommendations along four thematic lines.

1. What are the "big picture" science questions that are of global significance and can be addressed through scientific drilling in the SCS?

2. How can the drilling objectives, targets, and strategy of the IODP Proposal 735-CPP be prioritized? How can the site survey data be improved?

3. What are other future potential drilling objectives and targets in the SCS?
4. How can we strengthen future international cooperation in research of Southeast Asia and the SCS?

The workshop participants were divided into four subgroups, each of 15-18 members with mixed expertise. Key findings from the four subgroups were remarkably consistent, pointing to a prioritized strategy of scientific drilling in the SCS.

\section{Workshop Recommendations}

Through ample discussion at both plenary discussion and breakout sessions, the workshop reached a consensus on a prioritized ocean drilling strategy in the SCS with the following key recommendations.

\section{(1) The initial top drilling priority is to constrain the timing of the start and end of seafloor spreading events in the SCS.}

This objective can be achieved through a single expedition drilling into oceanic basement rocks in both the east and southwest sub-basins. It was felt that sampling and dating oceanic basement rocks through deep drilling is the only way to ground truth the hypothesized oceanic crust age, based on interpretation of magnetic anomalies.

(2) Transect drilling from the oldest visible seafloor-spreading magnetic anomaly to the extinct spreading axis of the SCS.

All four subgroups suggested that transect drilling should be conducted on both the east and southwest sub-basins

(3) The sedimentary sequences obtained while drilling into the oceanic basement should be effectively used for studying environmental history of the region.

The above recommendations (1) to (3) were later incorporated in the revised IODP Proposal 735-CPP-2 that was submitted to IODP in April 2012.

(4) The workshop recommended a phased drilling strategy, starting with a leg of drilling the oceanic crust (i.e., IODP Proposal 735-CPP-2) to be followed by future drilling of syn-rifting sequences and Mesozoic strata on both margins of the SCS.

The participants expressed strong interest in drilling syn-rifting sequences on conjugate margins of the SCS. Drilling targets should enable detailed comparison of extension histories on conjugate sides, aiming to document the full extension history of both margins.

Drilling into Mesozoic sediments also has its merits through providing constraints on the critical period before the SCS formation. Drilling the Mesozoic strata could help to test key questions regarding the connection of the Tethys to paleo-Pacific Ocean. Furthermore, evidence from Mesozoic strata could help to test tectonic models and to explore if there is evidence for pre-SCS extension in the Mesozoic. 
(5) The participants expressed interest in drilling targets associated with submarine hydrology and deep biosphere of the SCS.

It was felt that hydrology and deep biosphere are important objectives for future drilling in the SCS, but at present information is insufficient to define exact targets. Thus, it would be useful to combine biosphere and microbiological targets with other drilling sites.

Installation of a circulation obviation retrofit kit (CORK) was proposed to study the hydrology, deep biosphere, and carbon cycle. However, it was recognized that the installation of CORK observatories would require intensive effort, and thus careful planning of drilling objectives, sites, and strategy needs to be developed.

Overall, the workshop developed a strong sense of enthusiasm, both from participating scientists and institutions. Participants expressed confidence that if the first phase of drilling (IODP Proposal 735-CPP-2) is approved, subsequent proposals focused on drilling syn-rift sequences and Mesozoic strata and with hydrology/deep biosphere objectives would be developed.

\section{Progress Forward}

In April 2012, a revised IODP proposal entitled "Opening of the South China Sea and its implications for Southeast Asian tectonics, climates, and deep mantle processes since

the Late Mesozoic” was submitted to IODP. This revised proposal (Li et al., 2012) has incorporated all of the key recommendations of the workshop. Four primary and five alternate drilling sites in the SCS ocean basin were proposed, all aimed at reaching the oceanic basement in order to recover both oceanic basalts and overlying sediments. The revised proposal has adopted the recommended transect drilling strategy with drilling sites in both the east and southwest sub-basins (Figs. 1, 3).

The proposed drilling sites are designed strategically to determine timing of onset and termination of seafloor spreading in different sub-basins, and timing of a possible ridge jump or a volcanic event amid seafloor spreading. These sites will allow geochemical samplings of basement rocks of different ages, yielding critical information on how the crust and mantle have evolved over the time of basin formation. Together the drilling proposal will address research objectives in three major themes: (1) Cenozoic mechanisms, timings, sequences, and affiliations of seafloor spreading; (2) oceanic crustal accretion and mantle evolution; and (3) paleoceanographic and sedimentary responses to tectonic evolution of the SCS.

\section{Links to Other Programs}

There are currently several ongoing research programs in the region. One major initiative is the SCSD Program funded by the NSF-C. With a total budget of $\sim 25 \mathrm{M}$ USD,
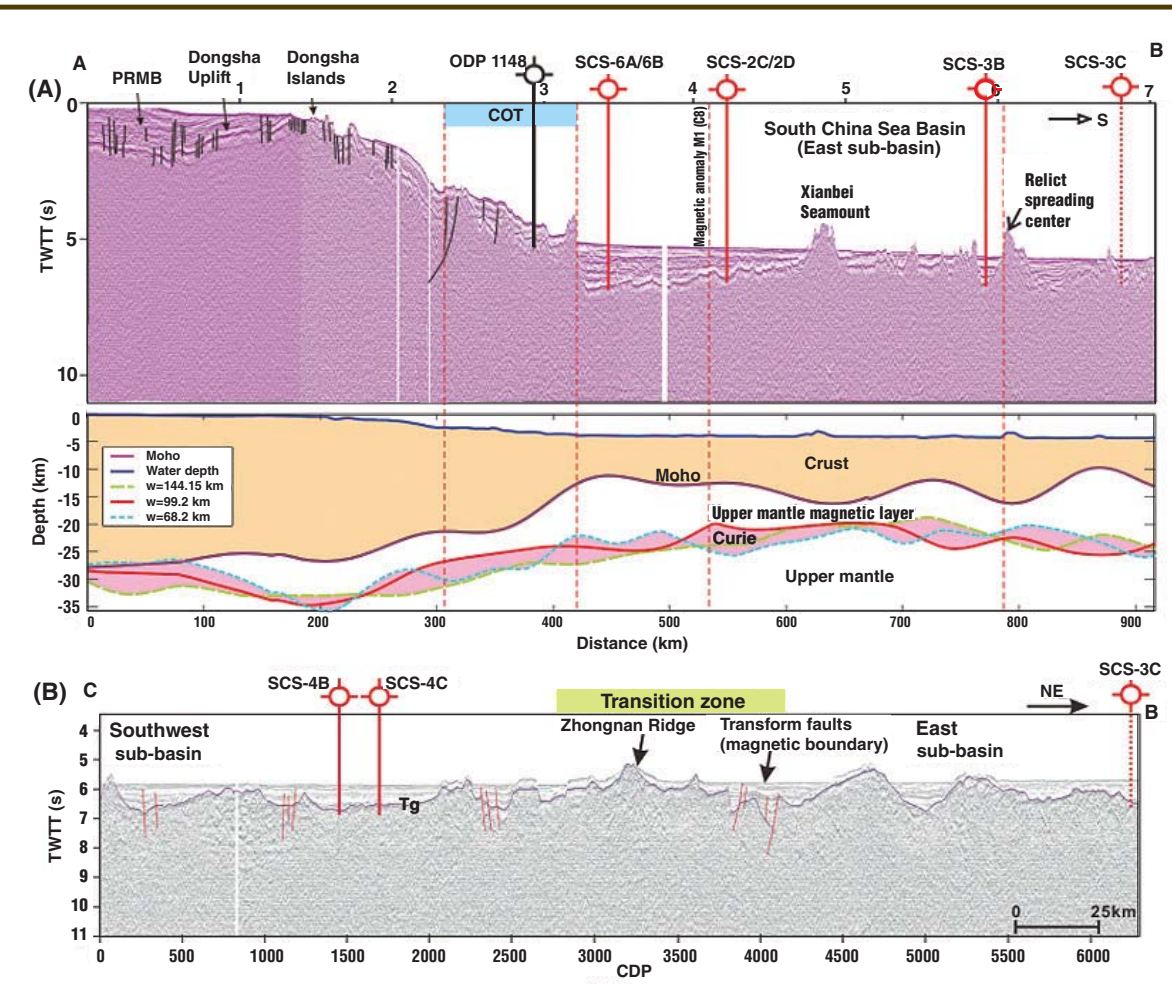

Figure 3. [A] (upper) Proposed sampling transect in the east sub-basin of the SCS (after Li et al., 2010). (lower) The Moho and Curie depths estimated from gravity and magnetic anomalies, respectively. TWTT=two-way travel time. COT=continent-ocean transition zone. PRMB=Pearl River Mouth Basin. w=width of moving windows in estimating Curie depths. [B] Seismic section showing the structures of the southwest sub-basin and the east sub-basin, as well as the transition zone between them. Tg is the Cenozoic basement (after Li et al., 2008). this eight-year research program (2011-2018) aims to reveal the life history of a classical marginal sea through research of the interconnection between tectonic/magmatic, sedimentological, and biochemical processes of the SCS (Wang, 2012). The SCSD Program is currently funding 3D Ocean Bottom Seismometers (OBS) experiments and deep-tow magnetics surveys in the east and southwest sub-basins of the SCS. The program will also sponsor additional site surveys and post-cruise research related to the proposed IODP drilling.

Following the Shanghai workshop, new site survey data related to the IODP Proposal 735-CPP-2 were provided by several institutions including the China National Offshore Oil Company (CNOOC), Guangzhou Marine Geological Survey (GMGS), National Central University in Taiwan, Federal Institute for Geosciences and Natural Resources (BGR), Germany, as well as by scien- 
tists on board a French R/V Marion Dufresne cruise in 2012. Acquisition of new site survey data was initiated by the proponents of the IODP Proposal 735-CPP-2 during the summer of 2012 .

\section{Acknowledgements}

The workshop was jointly sponsored and funded by the IODP-MI, IODP-China, the South China Sea Deep (SCSD) Program of the National Natural Science Foundation of China (NSF-C), and the State Key Laboratory of Marine Geology at Tongji University. We thank all workshop participants and co-proponents of the IODP Proposal 735-CPP-2 for major scientific input and suggestions.

\section{References}

Barkhausen, U., and Roeser, H.A., 2004. Seafloor spreading anomalies in the South China Sea revisited. In Clift, P., Kuhnt, W., Wang, P., and Hayes, D. (Eds.), Continent-Ocean Interactions within East Asian Marginal Seas, AGU Geophysical Monograph, 149: Washington, DC (American Geophysical Union), 121-125.

Briais, A., Patriat, P., and Tapponnier, P., 1993. Updated interpretation of magnetic anomalies and seafloor spreading stages in the South China Sea: Implications for the Tertiary tectonics of Southeast Asia. J. Geophys. Res., 98:6299-6328. doi:10.1029/92JB02280

Hall, R., 1996. Reconstructing Cenozoic SE Asia. In Hall, R., and Blundell, D.J., (Ed.) Tectonic Evolution of Southeast Asia. Geological Society of London, Special Publication, 106:153-184.

Holloway, N.H., 1982. North Palawan Block, Philippines--Its relation to the Asian mainland and role in evolution of South China Sea. AAPG Bull., 66:1355-1383.

Hsu, S.-K., Yeh, Y.-C., Doo, W.-B., and Tsai, C-H., 2004. New bathymetry and magnetic lineations identifications in the northernmost South China Sea and their tectonic implications. Mar. Geophys. Res., 25(1-2):29-44. doi:10.1007/s11001-005 $-0731-7$

Li, C.-F., and Song, T., 2012. Magnetic recording of the Cenozoic oceanic crustal accretion and evolution of the South China Sea basin. Chin. Sci. Bull., 57(24):3165-3181. doi:10.1007/ s11434-012-5063-9

Li, C.-F., Shi, X., Zhou, Z., Li, J., Geng, J., and Chen, B., 2010. Depths to the magnetic layer bottom in the South China Sea area and their tectonic implications. Geophys. J. Int., 182:1229-1247. doi:10.1111/j.1365-246X.2010.04702.x

Li, C.-F., Wang, P.X., Franke, D., et al., 2012. Opening of the South China Sea and its implications for Southeast Asian tectonics, climates, and deep mantle processes since the Late Mesozoic. IODP Complementary Project Proposal, \#735-CPP-2.

Li, C.-F., Zhou, Z., Li, J., Chen, B., and Geng, J., 2008. Magnetic zoning and seismic structure of the South China Sea ocean basin. Mar. Geophys. Res., 29:223-238. doi:10.1007/ s11001-008-9059-4

Shi, H., and Li, C.-F., 2012. Mesozoic and early Cenozoic tectonic convergence-to-rifting transition prior to opening of the
South China Sea. Int. Geol. Rev.,1:1-28. doi:10.1080/002068 14.2012.677136

Smith, W.H.F., and Sandwell, T.D., 1997. Global seafloor topography from satellite altimetry and ship depth soundings. Science, 277:1957-1962. doi:10.1126/science.277.5334.1956

Tapponnier, P., Peltzer, G., Le Dain, A.Y., Armijo, R., and Cobbold, P., 1982. Propagating extrusion tectonics in Asia: New insights from simple experiments with plasticine. Geology, 10:611616. doi:10.1130/0091-7613(1982)10\%3C611:PETIAN\%3E2. $0 . \mathrm{CO} ; 2$

Taylor, B., and Hayes, D.E., 1983. Origin and history of the South China Sea basin. In Hayes, D.E. (Ed.) The Tectonic and Geologic Evolution of Southeast Asian Seas and Islands II, AGU Geophysical Monograph, 27: Washington, DC (American Geophysical Union), 23-56. doi:10.1029/ GM027p0023

Taylor, B., and Hayes, D.E., 1980. The tectonic evolution of the South China Sea basin. In Hayes, D.E. (Ed.) The Tectonic and Geologic Evolution of Southeast Asian Seas and Islands, AGU Geophysical Monograph, 23: Washington, DC (American Geophysical Union), 89-104. doi:10.1130/00917613(1982)10\%3C611:PETIAN\%3E2.0.CO;2

Wang, P.X., 2012. Tracing the life history of a marginal sea - On the South China Sea Deep Research Program. Chin. Sci. Bull., 57:1-22, doi:10.1007/s11434-012-5087-1

Wang, P.X., and Li, Q.Y., 2009. The South China Sea: Paleoceanography and Sedimentology: Springer, pp. 506.

Wang, P.X., Prell, W., Blum, P., et al., 2000. Proc. ODP, Init. Repts., 184: College Station, TX (Ocean Drilling Program). doi:10.2973/odp.proc.ir.184.2000

Yao, B., Zeng, W., Hayes, D., et al. 1994. The Geological Memoir of South China Sea Surveyed Jointly by China and USA (in Chinese). Wuhan, (China University of Geoscience Press).

\section{Authors}

Jian Lin, Woods Hole Oceanographic Institution, Department of Geology \& Geophysics, Woods Hole, MA 02543, U.S.A., e-mail: jlin@whoi.edu (Corresponding Author)

Chun-Feng Li, Tongji University, State Key Laboratory of Marine Geology, 1239 Siping Road, Shanghai 200092, China, e-mail: cfl@tongji.edu.cn

Pinxian Wang, Tongji University, State Key Laboratory of Marine Geology, 1239 Siping Road, Shanghai 200092, China, e-mail: pxwang@tongji.edu.cn

Dieter Franke, Federal Institute for Geosciences and Natural Resources (BGR), Stilleweg 2, 30655 Hannover, Germany, e-mail: Dieter.Franke@bgr.de

Jun Tian, Tongji University, State Key Laboratory of Marine Geology, 1239 Siping Road, Shanghai 200092, China, e-mail: tianjun@tongji.edu.cn

\section{Related Web Links}

http://www.iodp-china.org/ http://www.iodp.org/workshops/ 